\title{
Suppressing Hydrogen Evolution by Aqueous Silicon Powder Dispersions by Controlled Silicon Surface Oxidation
}

\author{
Shepherd M. Tichapondwa ${ }^{1}$, Walter W. Focke ${ }^{1, *}$, Olinto Del Fabbro ${ }^{1}$ and Elmar Muller ${ }^{2}$ \\ ${ }^{1}$ Institute of Applied Materials, Department of Chemical Engineering, University of Pretoria, \\ Lynnwood Road, Pretoria, South Africa \\ ${ }^{2}$ Research and Technology, AEL Mining Services, PO Modderfontein, 1645, South Africa
}

\begin{abstract}
Aqueous silicon dispersions are used to produce pyrotechnic time delay compositions. The propensity of the silicon to react with water and to produce hazardous hydrogen gas must be suppressed. To this end, the effect of air heat treatment temperature on the rate of corrosion of silicon was investigated. It was found that four hour heat treatments at temperatures below $350^{\circ} \mathrm{C}$ provided significant passivation. This is attributed to the removal of the hydroxyl groups present on the $\mathrm{SiO}_{2}$ surface scale layer. It was found that thickening the silica layer, by heat treatment at higher temperatures, causes a further reduction in the amount of hydrogen released. However, differential thermal analysis (DTA) studies showed that excessive silicon surface oxidation increased the ignition temperature and reduced the heat release of a near-stoichiometric Si-lead chromate pyrotechnic composition.
\end{abstract}

Keywords: Silicon, Silicon dioxide, Hydrogen, Pyrotechnics

\footnotetext{
*Corresponding author; e-mail: walter.focke@up.ac.za
} 


\section{Introduction}

Silicon powder has found extensive use as fuel in pyrotechnic compositions [1]. Of special interest is its use in mine detonator time delay compositions [1, 2]. Such delay elements are currently manufactured by pressing the pyrotechnic composition into aluminium tubes. The automated filling and pressing process requires powders with good free flow behaviour. Spray drying of slurries is an appropriate method to obtain such free flowing granules as it creates almost perfect spherical particle agglomerates [3]. In addition to the acceptable flow properties, this process also yields well-mixed compositions from dispersions containing different powders and provides control over the agglomerate particle size distribution. The spray drying process requires that the silicon fuel and other constituents be slurried in water $[3,4]$. This creates a potential hazard situation as oxygen-containing water reacts dissociatively with silicon to form $\mathrm{SiO}_{2}$ and hydrogen gas [5]. The overall reaction is given in Scheme I:

$$
\mathrm{Si}+1 / 2 \mathrm{O}_{2}+\mathrm{H}_{2} \mathrm{O} \rightarrow \mathrm{SiO}_{2}+\mathrm{H}_{2} \uparrow
$$

Scheme I: Overall silicon oxidation reaction with oxygen containing water.

The evolved hydrogen presents an explosive hazard during the production process. $\mathrm{H}_{2}+$ air gas mixtures can support deflagration in the concentration range $4 \%-75 \%$ (volume hydrogen fuel basis) [6].

Corrosion inhibition by means of protective coatings, that separate susceptible surfaces from the factors that cause corrosion in the surrounding environment, is well documented [7]. Mack et al. [8] and Gruvin et al. [9] report that silicon, just like metals such as aluminium and titanium forms an adherent oxide cover that protects the underlying 
substrate from further corrosion. Methods for creating a silicon oxide layer on a silicon substrate have been extensively explored $[10,11]$. They include thermal oxidation, chemical vapour deposition, ozonation, $\mathrm{H}_{2} \mathrm{O}_{2}$ and nitric acid oxidation, etc. Thermally produced $\mathrm{SiO}_{2}$ is said to have the best passivating effect [12] and has been shown to reduce the amount of hydrogen evolved when coated silicon powders are placed in water [13]. In these studies the aim was to prevent the silicon passivation to enhance hydrogen evolution.

Silicon undergoes oxidation at room temperature as in the presence of oxygen, water or both. The rate of oxidation of silicon increases with increase in temperature [14]. Continued oxidation leads to thickening of the oxide layer [15]. Silicon thermal oxidation is initially a surface reaction which changes over to a diffusion controlled reaction at the silicon-silicon dioxide interface. Oxygen or water must diffuse through the $\mathrm{SiO}_{2}$ layer to reach the Si below for reaction to take place. The diffusion coefficient of oxidant through the $\mathrm{SiO}_{2}$ layer is relatively low at room temperature but increases with temperature [16]. A number of silicon oxidation models have been developed, however the Deal and Grove linear - parabolic model is the most widely used [16].

The objective of this investigation was to establish the effect of varying the heat treatment temperature on the amount of hydrogen evolved by of a commercial silicon powder when dispersed in water. The effect of surface oxidation on the burn behaviour of a silicon based pyrotechnic composition was also studied by differential thermal analysis (DTA).

\section{Experimental}

\subsection{Materials}

Ball milled Type 4 silicon was supplied by Millrox. It had a $d_{50}$ particle size of 2.06 $\mu \mathrm{m}$ (Mastersizer Hydrosizer 2000) and a specific surface area of $9.68 \mathrm{~m}^{2} / \mathrm{g}$ (Nova $1000 \mathrm{e}$ BET, $\mathrm{N}_{2}$ at $\left.77 \mathrm{~K}\right)$. Rolfes Pigments supplied lead chromate $\left(\mathrm{PbCrO}_{4}\right)$ in the form of grade 
Middle Chrome L-GXD. The pigment had a $\mathrm{d}_{50}$ particle size of $2.14 \mu \mathrm{m}$ (Mastersizer Hydrosizer 2000) and a BET specific surface area of $16.7 \mathrm{~m}^{2} / \mathrm{g}$. The distilled water was obtained from a laboratory still. A Si $+\mathrm{PbCrO}_{4}$ pyrotechnic composition with $20 \mathrm{wt} \% \mathrm{Si}$ was prepared. One gram of mixture was dry mixed by passing it through a $75 \mu \mathrm{m}$ sieve several times.

\subsection{Hydrogen Evolution}

Hydrogen evolution studies were performed by placing $40 \mathrm{~g}$ of neat or heat treated silicon powder in a $250 \mathrm{~mL}$ flask and immersing it in an ultrasonic water bath with temperature maintained at $30^{\circ} \mathrm{C} \pm 1^{\circ} \mathrm{C}$. The flask was connected to an inverted graduated burette filled with water to an initial level. An aliquot $100 \mathrm{~mL}$ of distilled water was added to the silicon. The mixture was continuously agitated in a MRC D150H ultrasonic bath. The operating frequency was $43 \mathrm{kHz}$ and the power dissipation was $150 \mathrm{~W}$. The volume of water displaced by the gas in the inverted burette was recorded after 60 minutes. Each experiment was repeated at least five times for statistical purposes. The moles hydrogen produced per $\mathrm{kg}$ Si were calculated assuming that the ideal gas law applies.

\subsection{Powder Heat Treatment}

Samples of neat silicon powder (400 g) were measured out into alumina crucibles and heated in air at $75^{\circ} \mathrm{C}, 150^{\circ} \mathrm{C}, 250^{\circ} \mathrm{C}, 300^{\circ} \mathrm{C}, 350^{\circ} \mathrm{C}, 450^{\circ} \mathrm{C}$ and $550^{\circ} \mathrm{C}$ for 4 hours. The amount of surface oxide formed on the silicon powder was determined as follows. Approximately $0.5 \mathrm{~g}(500 \mathrm{mg})$ of silicon powder was contacted with $10 \mathrm{~mL}$ of $10 \mathrm{wt} \% \mathrm{HF}$ to selectively remove the $\mathrm{SiO}_{2}$ by etching [17]. The mixture was agitated for 10 minutes and 
then centrifuged. The resultant solution was analysed for the Si concentration using Inductively Coupled Plasma Optical Emission Spectroscopy (ICP-OES).

\subsection{Characterization}

The surfaces of the heat-treated and neat silicon powders were analysed by Diffuse Reflectance Infrared Fourier Transform analysis (DRIFT) on a Perkin-Elmer Spectrum 2000GX FTIR spectrometer. The ratio of sample mass to KBr mass was 1:20. All FTIR spectra were recorded at a resolution of $2 \mathrm{~cm}^{-1}$ from 4000 to $450 \mathrm{~cm}^{-1}$ and represent the average of 30 scans.

Differential thermal analysis (DTA) was carried out using a Shimadzu DTA-50 instrument. Approximately $5 \mathrm{mg}$ each of sample and standard $\left(\alpha-\mathrm{Al}_{2} \mathrm{O}_{3}\right)$ were weighed into alumina sample pans. One $500 \mu \mathrm{m}$ thick copper disk was placed at the bottom of each of the sample pans. These acted as heat sinks to protect the DTA temperature detector from high temperature excursions [18]. The DTA runs were carried out in a nitrogen atmosphere and the temperature was scanned from ambient temperature to $1000^{\circ} \mathrm{C}$ at a scan rate of $50^{\circ} \mathrm{C} \mathrm{min}-$ ${ }^{1}$ with $\mathrm{N}_{2}$ flowing at a rate of $50 \mathrm{~mL} \mathrm{~min}^{-1}$.

Thermogravimetric analysis (TG) of the silicon powders was performed in an oxygen atmosphere using a combined dynamic and isothermal heating method on a Mettler Toledo A851 TG/SDTA instrument. About $20 \mathrm{mg}$ of powder was placed in open $70 \mu \mathrm{L}$ alumina crucibles. Temperature was scanned from 25 to $800^{\circ} \mathrm{C}$ at a rate of $50^{\circ} \mathrm{C} \min ^{-1}$ followed by temperature scan from 800 to $1200^{\circ} \mathrm{C}$ at a rate of $5^{\circ} \mathrm{C} \min ^{-1}$ and finally isothermal heating at $1200^{\circ} \mathrm{C}$ for 15 hours. The $\mathrm{O}_{2}$ flow rate was maintained at $50 \mathrm{~mL} \mathrm{~min}{ }^{-1}$.

A SPECTRO ARCOS Inductively Coupled Plasma Optical Emission Spectrometer (ICP-OES) was used to establish the quantity of $\mathrm{SiO}_{2}$ etched out following contacting with 
HF. Calibration with a multi-element standard (ICP grade) was carried out before running the leached samples. Samples were analyses in triplicate and the average ICP value was recorded.

A Zeiss AURIGA CrossBeam Workstation Focus Ion Beam - Scanning Electron Microscope (FIB-SEM) was used to first mill and then view the cross section of silicon particles treated at various temperatures. The powder samples were platinum coated using methyl cyclopentadienyl (trimethyl) platinum $\left(\mathrm{C}_{9} \mathrm{H}_{16} \mathrm{Pt}\right)$ before milling. A gallium source was used as the ion beam.

\section{Results}

\subsection{Effect of Surface Oxidation on $\mathrm{H}_{2}$ Evolution}

Figure 1 compares the volume of hydrogen produced from neat silicon to that produced from silicon powders heated in air at various temperatures before reaction. The results show that neat silicon produced $13.7 \pm 1.0 \mathrm{mmol} \mathrm{H}_{2} \mathrm{~kg}^{-1} \mathrm{Si}$ in one hour when ultrasonically agitated. This represents a $65 \%$ increase in the hydrogen gas output compared to the result previously reported using magnetic stirring [19] for the same powder. Thermally treating the silicon had varying effects on its reactivity towards water depending on the pretreatment temperature. Figure 1 shows two-step inhibition with an initial step decrease to 9.3 $\pm 0.4 \mathrm{mmol} \mathrm{H}_{2} \mathrm{~kg}^{-1} \mathrm{Si}$ for silicon heated at $75^{\circ} \mathrm{C}$, this was followed by a gradual decrease in gas evolved from silicon heated from $75^{\circ} \mathrm{C}$ to $300^{\circ} \mathrm{C}$. The gas evolved from silicon heated at $300^{\circ} \mathrm{C}$ was $5.6 \pm 0.4 \mathrm{mmol} \mathrm{H} \mathrm{kg}^{-1} \mathrm{Si}$. The second step decrease in the $\mathrm{H}_{2}$ release rate occurred between $300^{\circ} \mathrm{C}$ and $350^{\circ} \mathrm{C}$ with the gas evolved decreasing further to $2.1 \pm 0.2$

mmol $\mathrm{H}_{2} \mathrm{~kg}^{-1} \mathrm{Si}$. This represents an $85 \%$ decrease in hydrogen gas evolved compared to the 


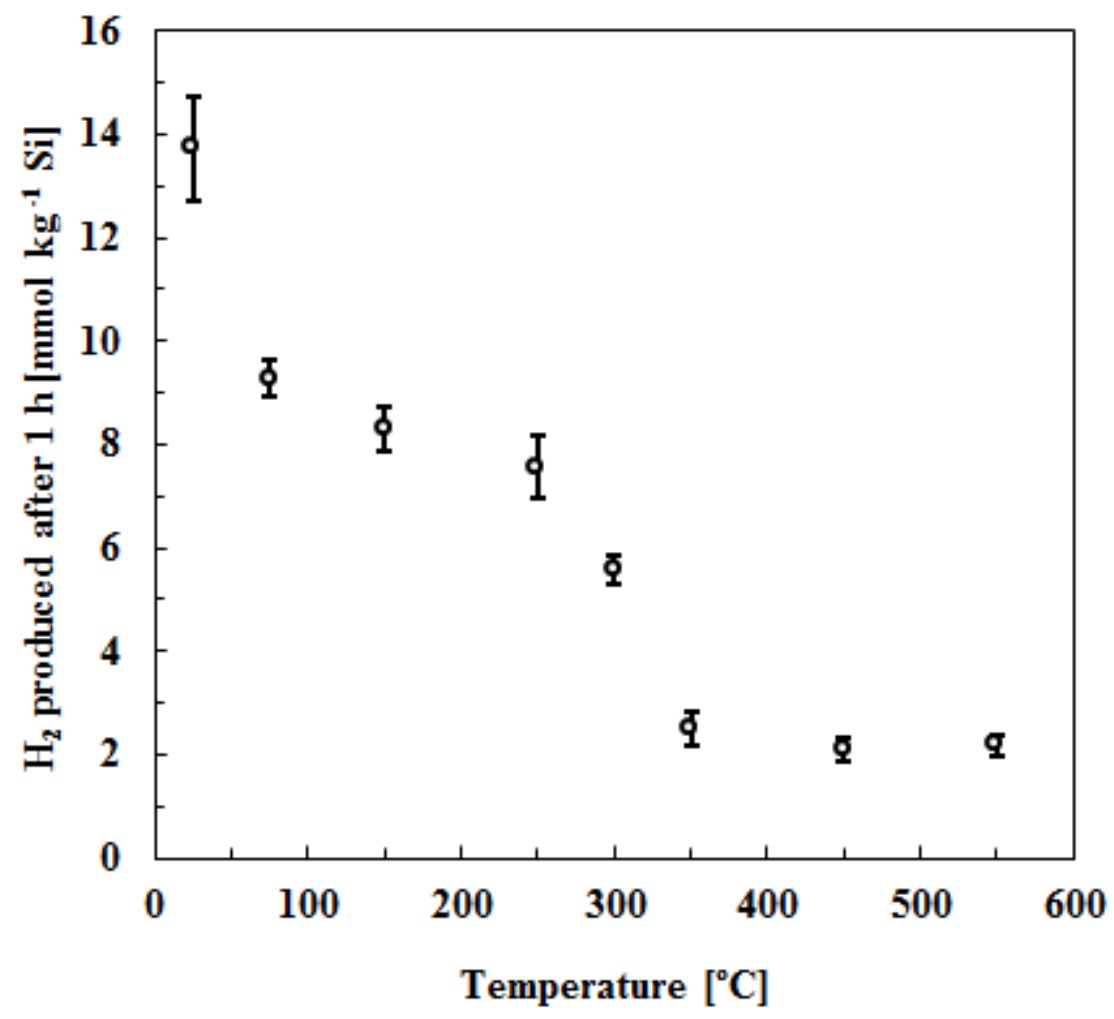

Figure 1. Quantity of hydrogen gas produced in $1 \mathrm{~h}$ from silicon powders heated for $4 \mathrm{~h}$ at varying temperatures when submersed in distilled water.

\subsection{Surface Characterization}

DRIFT spectra were recorded in order to assess the extent and the nature of the change brought about by the thermal treatments. Figure 2 shows DRIFT spectra for neat silicon and silicon powders heated at different temperatures in air. Consider first the spectrum obtained for the neat silicon. The band at $3400 \mathrm{~cm}^{-1}$ represents the $\mathrm{O}-\mathrm{H}$ stretch vibration of the $\mathrm{Si}-\mathrm{OH}$ surface bond. The absorption intensity of this band decreased with increasing heat treatment temperature from neat silicon to silicon heated at $250{ }^{\circ} \mathrm{C}$. The band location showed a slight shift to lower wave numbers while the intensity decreased sharply for silicon powders heated at $300^{\circ} \mathrm{C}$ and above. This indicates progressive removal of the surface silanol groups. A broad band from $1000-1300 \mathrm{~cm}^{-1}$ (asymmetric Si-O-Si stretch vibration) was 


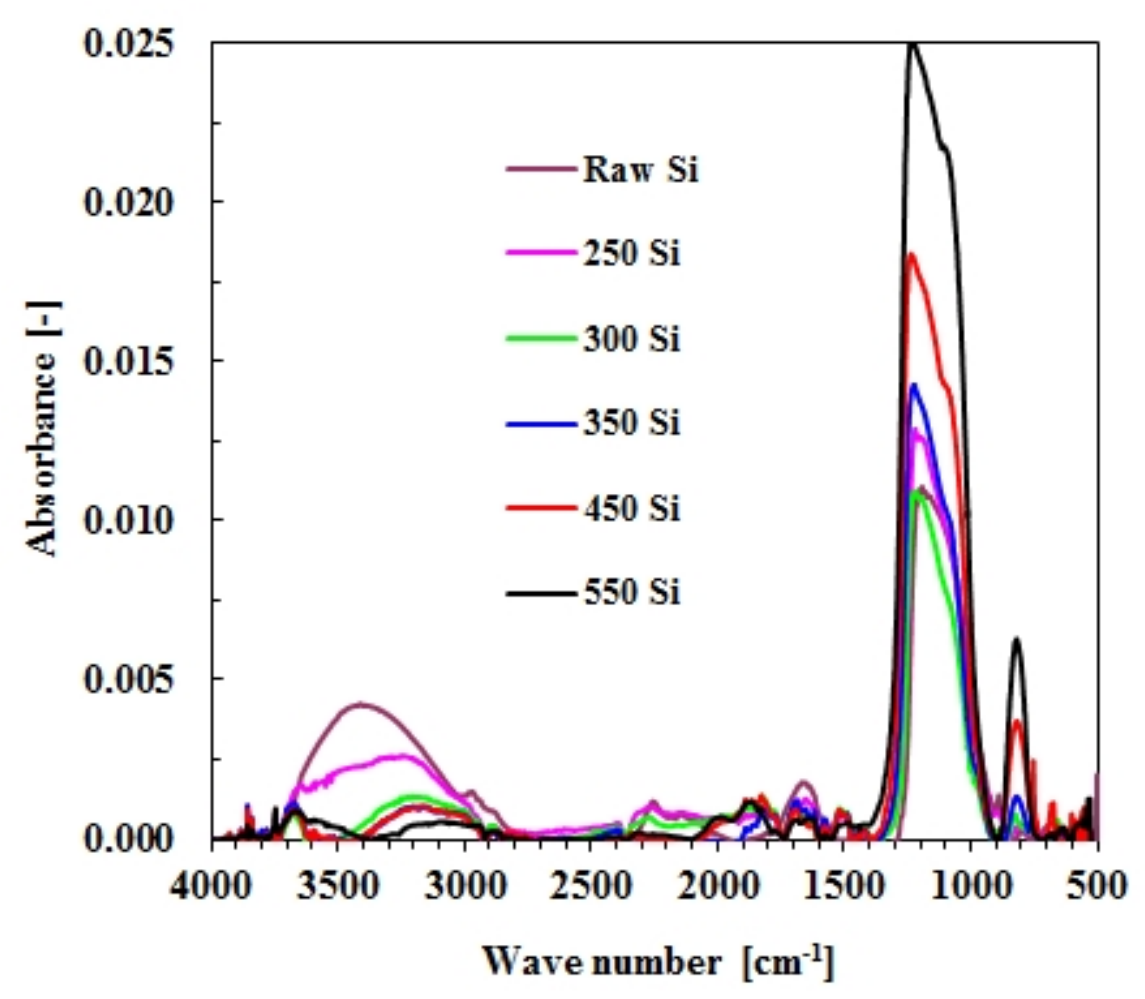

Figure 2. DRIFT spectra for silicon powder surfaces heat-treated at various temperatures.

observed in all the silicon powders characterised. This confirms the presence of $\mathrm{SiO}_{2}$ on the surface of the silicon [5]. Figure 3 shows the variation of the absorbance of the $\mathrm{Si}-\mathrm{O}-\mathrm{Si}$ band $1000-1300 \mathrm{~cm}^{-1}$ with increase in heat treatment temperature. The observed absorbance for neat silicon and samples heat treated at $300^{\circ} \mathrm{C}$ or below were similar. This suggests that, in this temperature range, the silica scale layer did not increase much in thickness. Above $300^{\circ} \mathrm{C}$ a distinct increase in absorbance of this band is evident. This increase parallels a similar intensity increase of the Si-O-Si bending band $\left(650-820 \mathrm{~cm}^{-1}\right)$ from 350 to $550^{\circ} \mathrm{C}$. These observations indicate that the degree of surface oxidation increased from $350^{\circ} \mathrm{C}$ and beyond. 


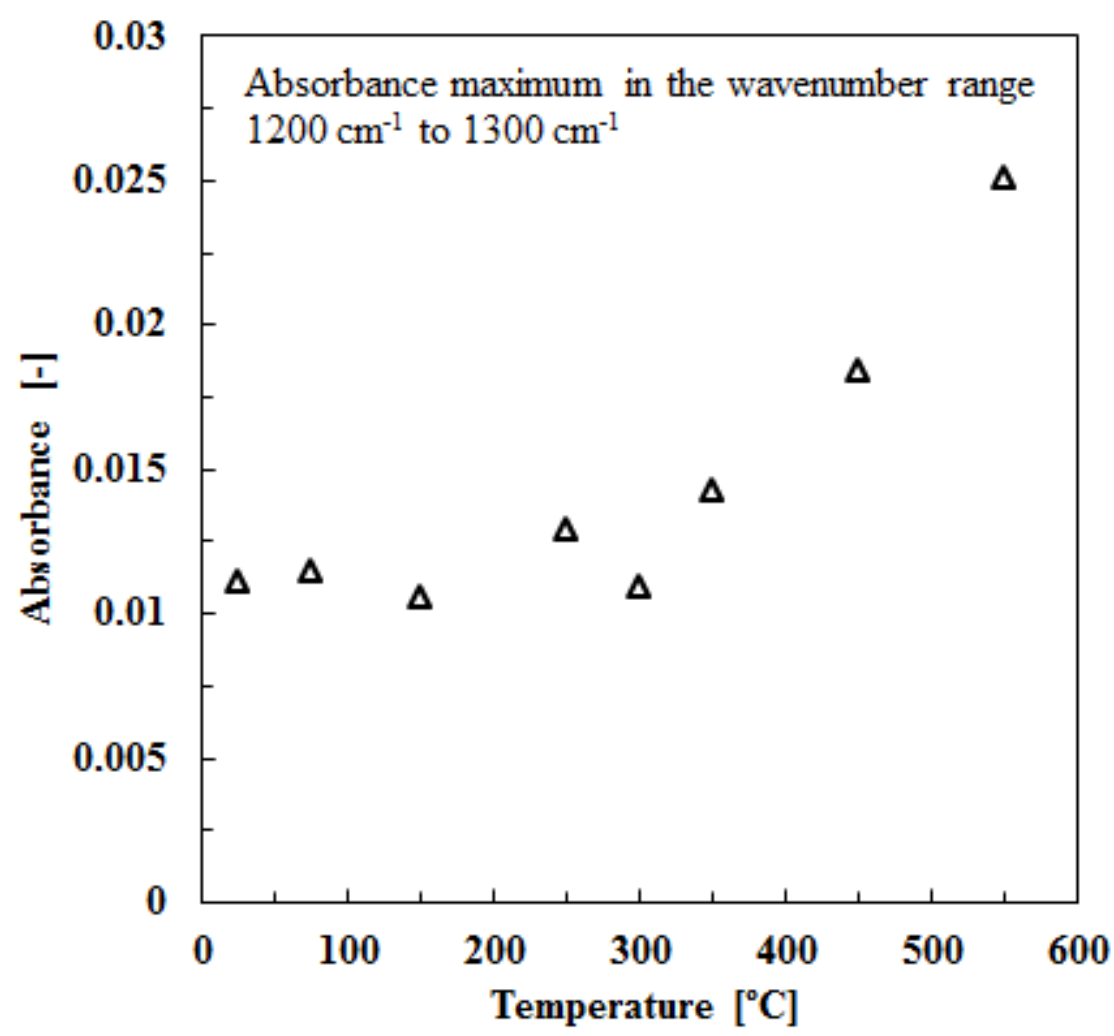

Figure 3. Variation of the maximum absorbance of the Si-O-Si band $\left(1200-1300 \mathrm{~cm}^{-1}\right)$ with pre-treatment temperature.

\subsection{Quantification of Silicon Oxidation}

TG analysis was used to estimate the extent of oxidation of the silicon powder. This was done by measuring the total oxygen uptake from the mass increase observed in the TG runs and relating that to the amount of silicon reacted according to Scheme I.

Figure 4 shows TG results obtained when oxidising neat silicon and the powder obtained after a four hour heat treatment at $550^{\circ} \mathrm{C}$. Little oxidation occurred during the initial fast dynamic heating step. The mass increase for neat silicon was only $2.6 \%$ during this stage. However, significant silicon oxidation occurred during the second slower dynamic heating step. This resulted in a total $49.1 \%$ mass increase for the neat silicon. Over time the isothermal stage also resulted in significant silicon oxidation, ultimately reaching $87.0 \%$ for neat silicon. Figure 4 shows that the TG curves of neat $\mathrm{Si}$ and silicon heat treated at $550^{\circ} \mathrm{C}$ 


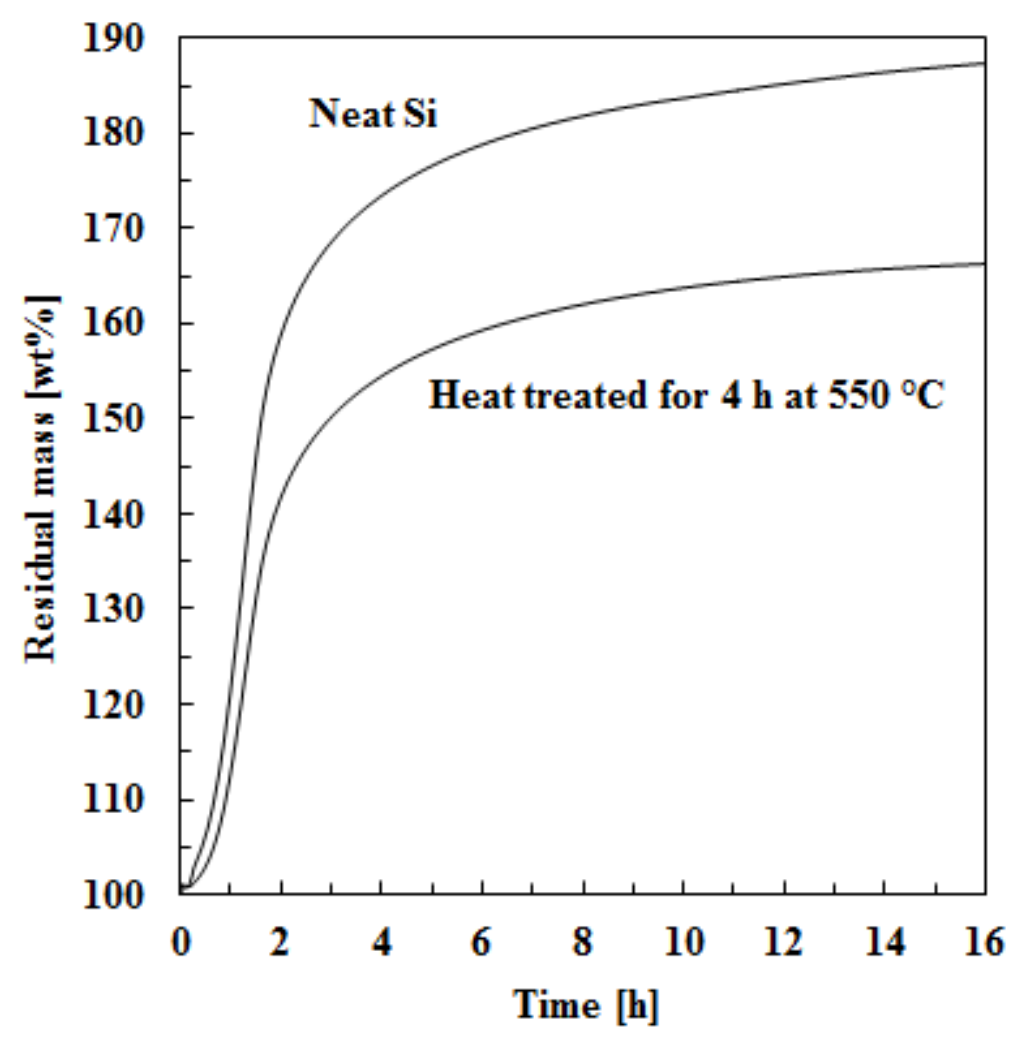

Figure 4. TG curves for neat silicon and $550^{\circ} \mathrm{C}$ treated silicon when heated in an oxygen atmosphere. (Vertical line indicates the start of isothermal heating).

were similar in shape but showed a different overall mass gain. This indicates that the mass of Si available for reaction with oxygen was different. Figure 5 reports silicon content values calculated on the assumption that complete conversion was achieved by the end of the TG runs. The slight difference between the two curves during the dynamic scans indicates that the preformed oxide layer had an effect on the rate of oxidation of the underlying Si.

Inductively Coupled Plasma - Optical Emission Spectroscopy (ICP-OES) was also used to quantify the extent of surface oxidation resulting from the heating processes. The silica layer on the silicon powders was etched away with $10 \%$ hydrofluoric acid solution according to Scheme II. While HF reacts with $\mathrm{SiO}_{2}$, it does not attack Si leaving it instead with a passive layer of surface hydrides [17]. 


$$
\mathrm{SiO}_{2}+6 \mathrm{HF} \rightarrow \mathrm{H}_{2} \mathrm{SiF}_{6}+2 \mathrm{H}_{2} \mathrm{O}
$$

Scheme II: Reaction of HF with $\mathrm{SiO}_{2}$.

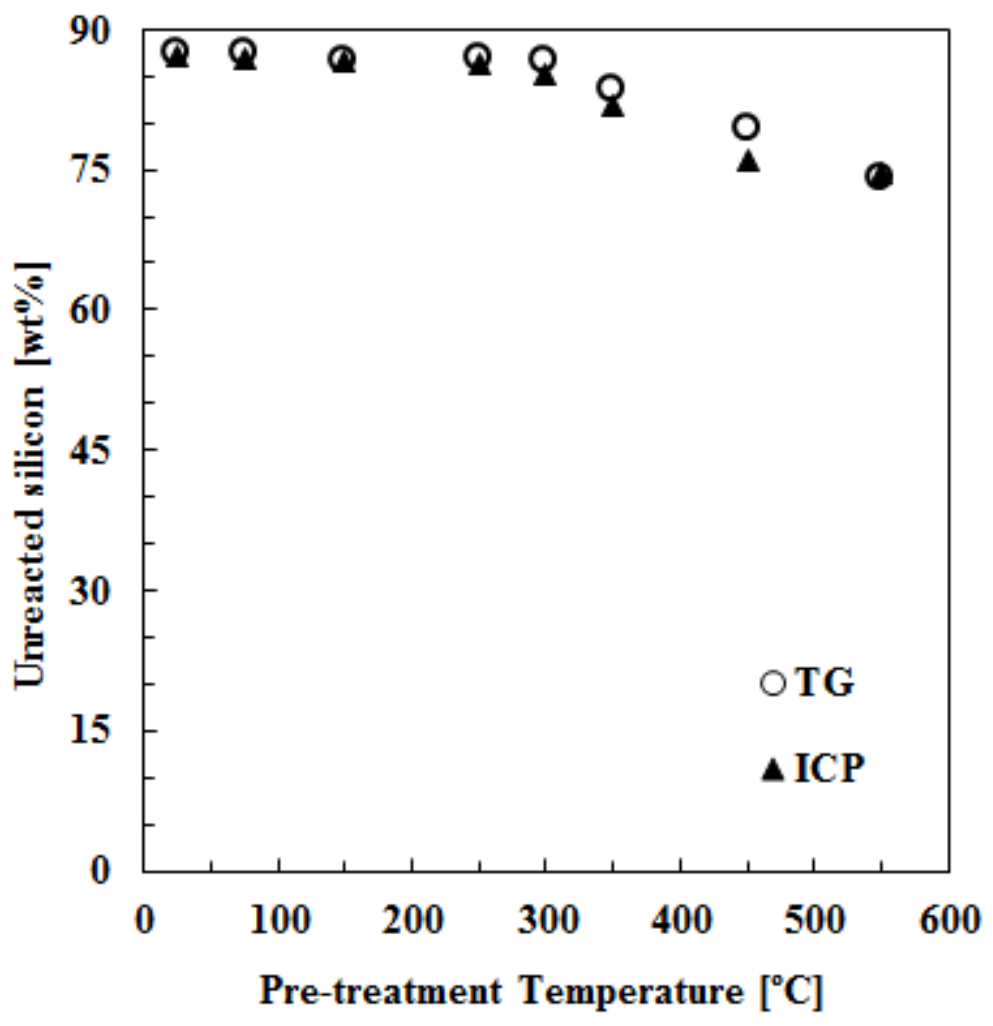

Figure 5. Amount of unreacted silicon present after thermal treatment at various temperatures based on TG and ICP analysis.

The concentration of Si in the etch solution was determined using ICP-OES. These results were then used to estimate the concentration of the $\mathrm{Si}$ associated with $\mathrm{H}_{2} \mathrm{SiF}_{6}$. The ICPmeasured concentration was then used to estimate the $\mathrm{SiO}_{2}$ content of the original silicon powder. The assumption was that the HF removed all of the silica. The results are presented in Figure 5. The unreacted silicon content values determined via these two methods were in close agreement. It was found that the neat silicon powder is already significantly oxidised. About $13 \%$ of the neat silicon had already been converted to $\mathrm{SiO}_{2}$ before any thermal treatment. The quantities of unreacted silicon obtained between neat silicon and silicon heated to $300^{\circ} \mathrm{C}$ are almost identical with an average of $87.0 \pm 0.4 \%$ for TG and $86.4 \pm 0.8 \%$ for ICP, respectively. This implies that no noticeable oxidation occurred at this heat treatment 
temperature or below. These results are consistent with the DRIFT data. A significant decrease in unreacted silicon is observed when the silicon is heat treated at $350^{\circ} \mathrm{C}$. The change, compared to the neat silicon, amounted to $3.32 \%$ and $4.59 \%$ according to the TG and ICP results respectively. Further increase in preheat temperature resulted in even greater extents of silicon oxidation. The silicon content of the sample heat treated at $450^{\circ} \mathrm{C}$ silicon decreased by $7.6 \%$ and $10.5 \%$ according to TG and ICP respectively. The corresponding values for heat treatment at $550^{\circ} \mathrm{C}$ were $12.8 \%$ and $11.7 \%$. These observations are consistent with the trend indicated by DRIFT.

\subsection{FIB-SEM Images}

Figure 6 shows the cross sectional SEM images obtained after milling selected silicon powder particles heat treated at different temperatures. The cross section for neat silicon, $150^{\circ} \mathrm{C}$ and $250^{\circ} \mathrm{C}$ treated silicon shown in Figures 6 (a), (b) and (c) did not show any detectable oxide layer formation. This suggests that no significant oxidation occurred at these temperatures. This observation is consistent with the results obtained from DRIFT, TG and ICP characterization. However, it was expected that a detectable oxide film would be present on the neat $\mathrm{Si}$ since approximately $13 \%$ of the $\mathrm{Si}$ was already converted into oxide. The apparent absence of a perceptible oxide layer on the large particle might be due to the relatively wide particle size distribution of the silicon powder (Figure 7). The smaller particles with higher specific surface areas and greater surface activity were probably more susceptible to oxidation and had a greater specific surface area available for oxidation than the large particles that were selected for milling with the ion beam [20]. However, a thin film

of the deposited Pt is observed. A thin oxide layer was observed on the silicon heated at $350^{\circ} \mathrm{C}$ (Figure $6(\mathrm{~d})$ ). Thicker oxide layers were also detected on the silicon powders heated at 450 and $550^{\circ} \mathrm{C}$, respectively. This indicates increased surface oxidation and these 
observations confirm earlier characterizations and give a clear indication that increased $\mathrm{SiO}_{2}$ thickness results in decreased hydrogen evolution.

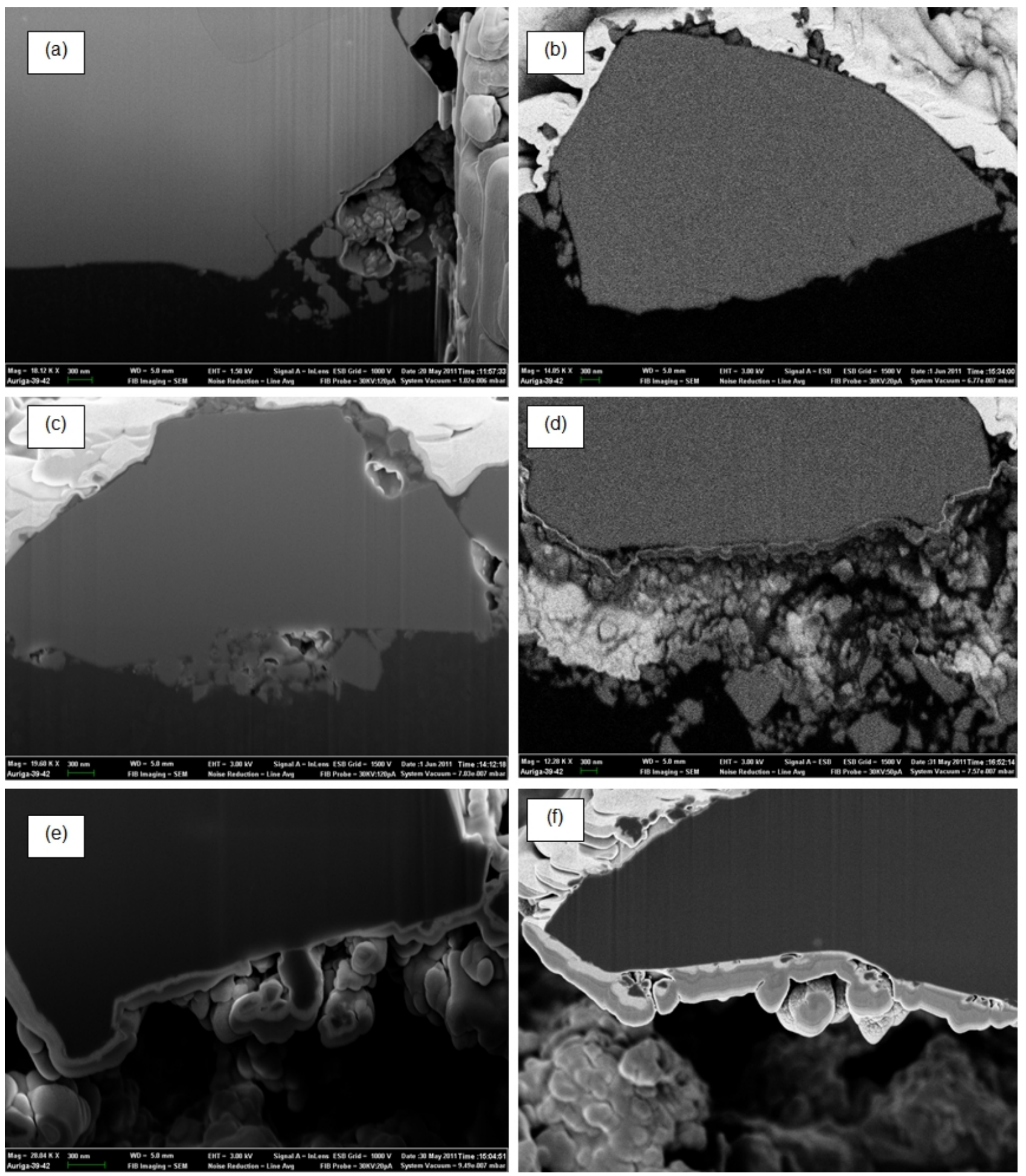

Figure 6. FIB-SEM images showing the cross section of milled neat silicon particles (a), as well as silicon particles heat treated at (b) $150^{\circ} \mathrm{C}$, (c) $250^{\circ} \mathrm{C}$, (d) $350^{\circ} \mathrm{C}$, (e) $450^{\circ} \mathrm{C}$ and (f) $550^{\circ} \mathrm{C}$, respectively. Note the development of a lighter coloured oxide layer at the bottom edge of particles shown in micrographs (d) to (f). 


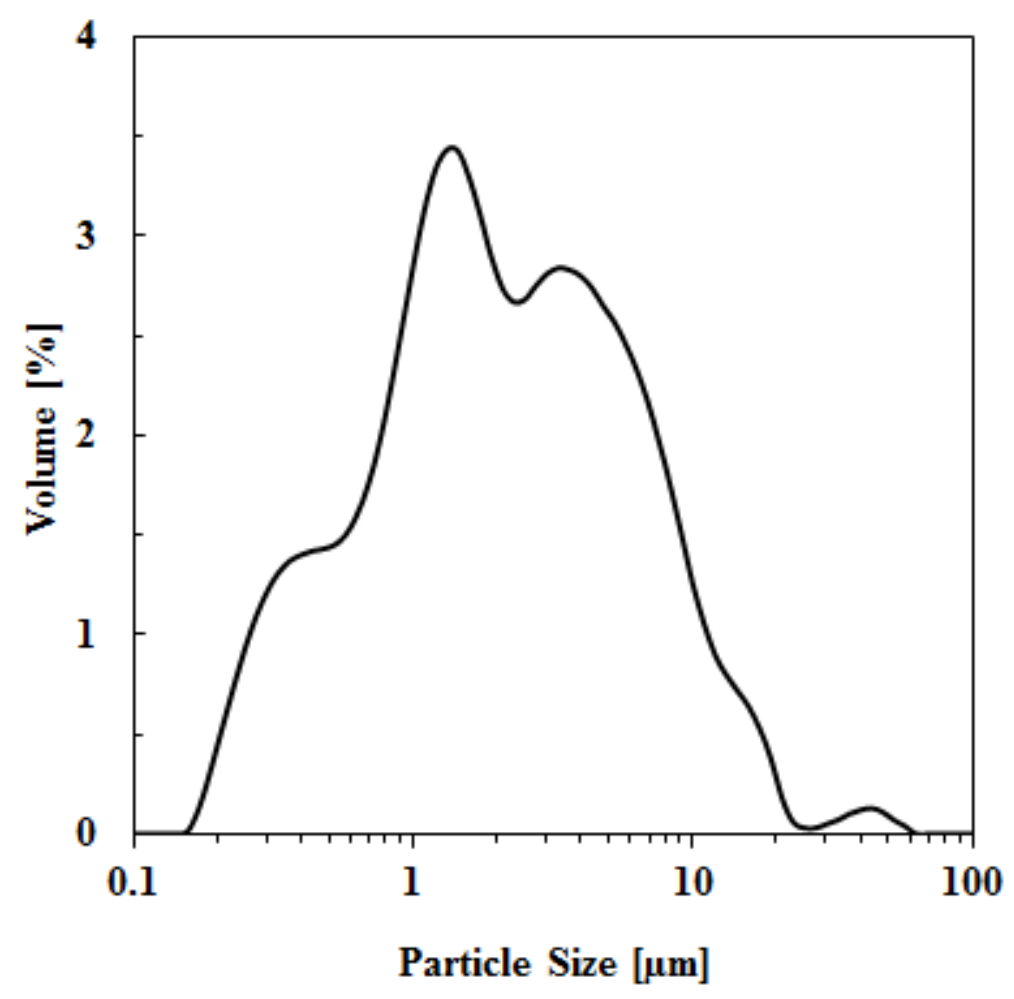

Figure 7. Particle size distribution of neat silicon.

\subsection{Differential Thermal Analysis Results}

A pyrotechnic composition of silicon and lead chromate $\left(\mathrm{PbCrO}_{4}\right)$ was used to establish the effect of preheating silicon powders in air on the DTA response of the composition. Typical DTA responses are shown in Figure 8. The silicon powders heat treated at $75^{\circ} \mathrm{C}$ and $300^{\circ} \mathrm{C}$ show very similar DTA traces except that the onset temperature is more than $20^{\circ} \mathrm{C}$ higher. The shape of the DTA traces take on a distinctly bimodal form for silicon heat treated at $350^{\circ} \mathrm{C}$ and above. The reason for this is not understood at present. The variation of the reaction onset temperature with silicon pre-heat temperature is shown in Figure 9. Neat silicon as fuel gives an exothermic peak with an ignition temperature of about $655^{\circ} \mathrm{C}$. The onset temperature increases approximately linearly with heat treatment 


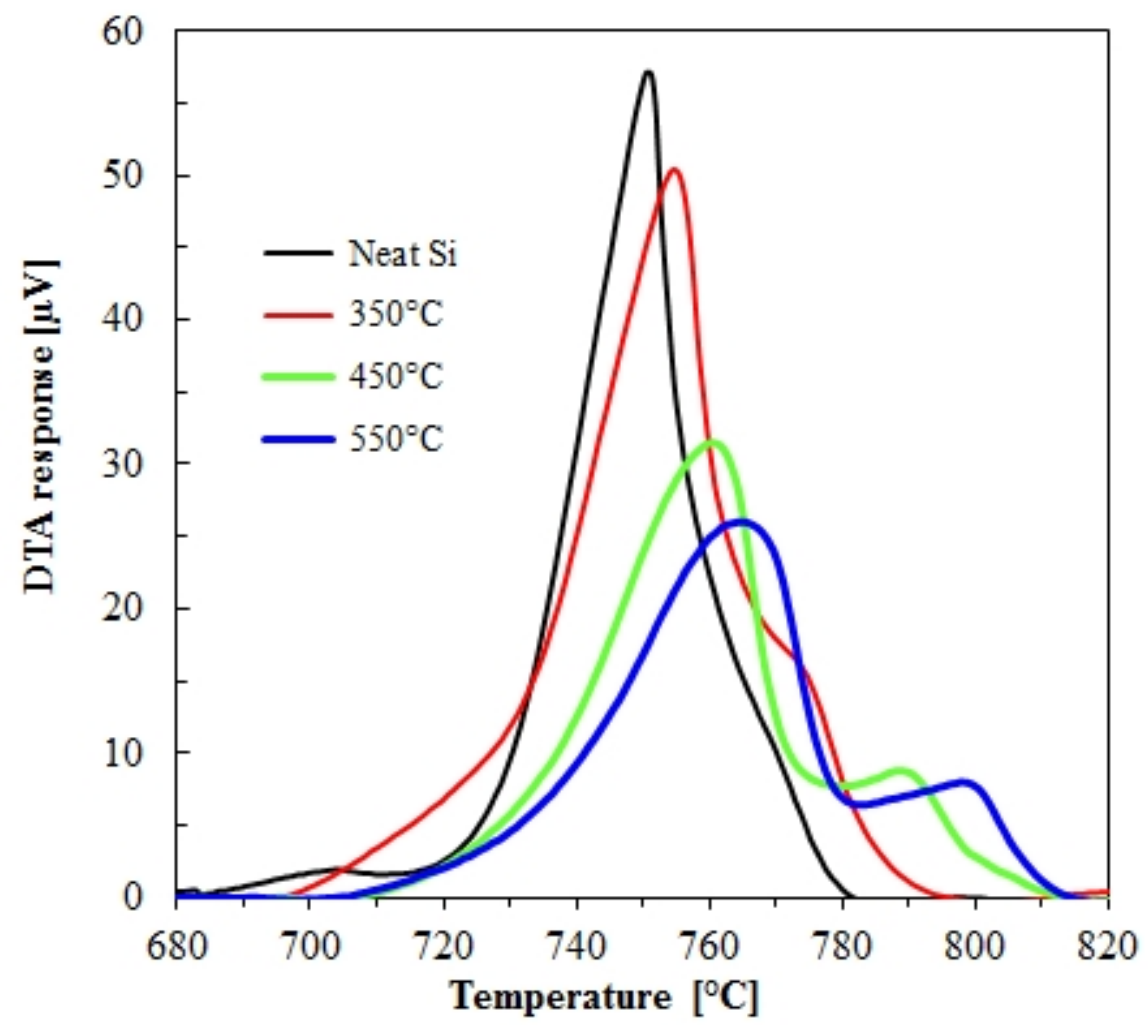

Figure 8. DTA characterization of $20 \mathrm{wt} \% \mathrm{Si}$ (preheated at different temperatures) $+80 \mathrm{wt} \%$ $\mathrm{PbCrO}_{4}$ pyrotechnic compositions in a nitrogen atmosphere and a temperature scan rate of $50^{\circ} \mathrm{C} \mathrm{m^{-1 }}$.

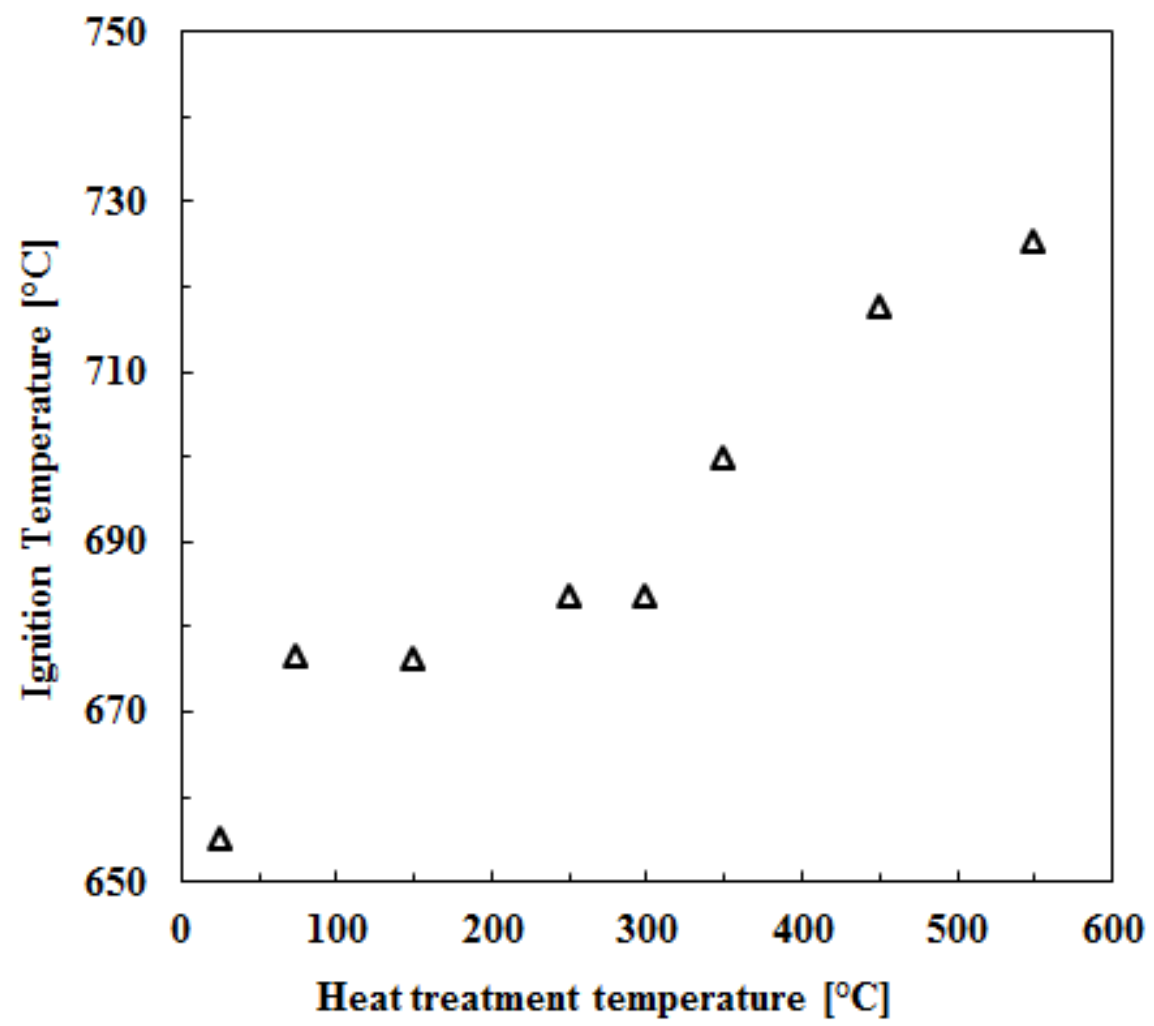

Figure 9. Variation of the ignition temperature with silicon powder pre-treatment temperature. 


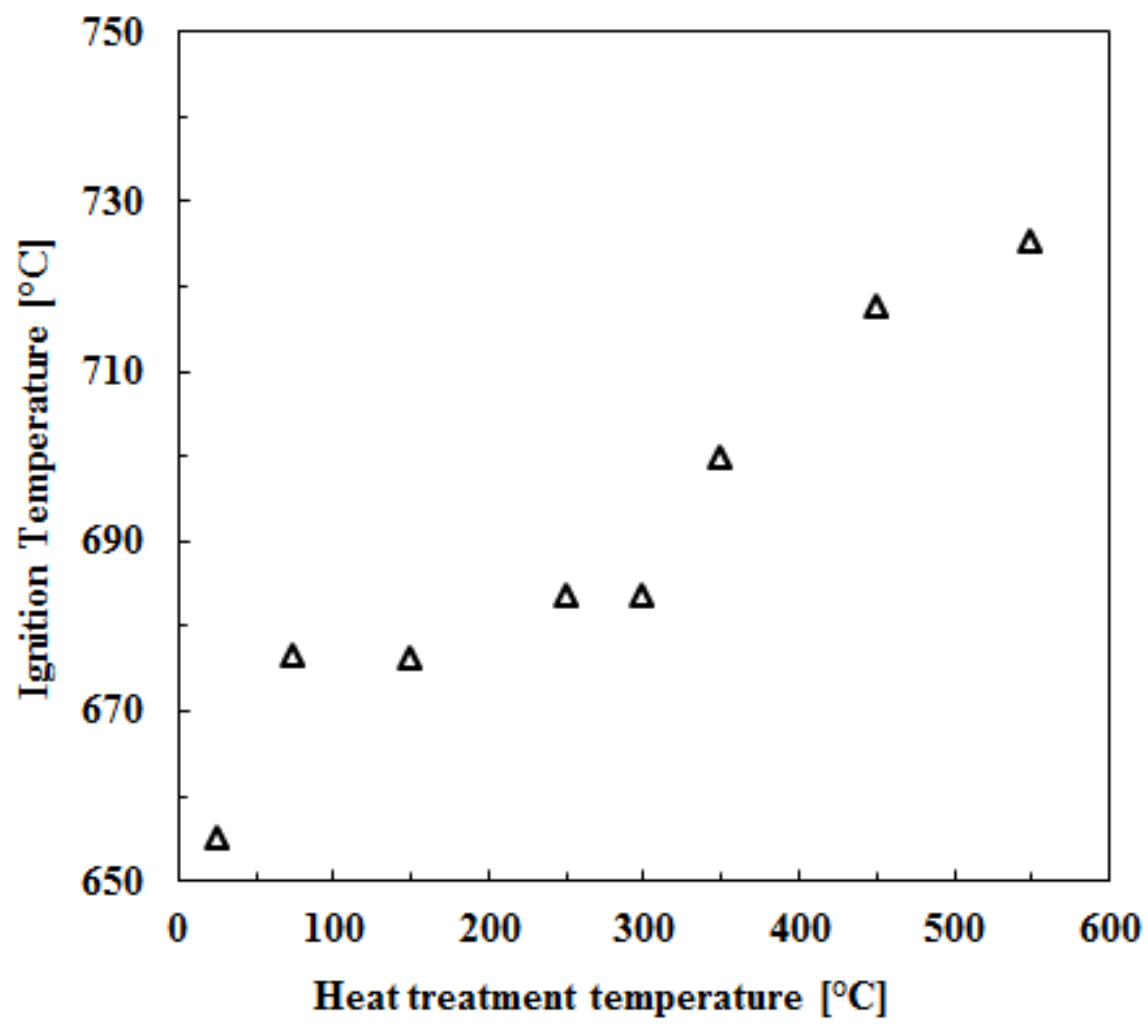

Figure 10. The unreacted silicon available in the powder after preheating at various temperatures and the heat released by a corresponding $20 \mathrm{wt} \% \mathrm{Si}+80 \mathrm{wt} \% \mathrm{PbCrO}_{4}$ pyrotechnic composition.

temperature of $250^{\circ} \mathrm{C}$ and higher. The apparent heat of the reaction (Figure 10) was estimated from the area under the DTA curves [21]. The heats of reaction, for the compositions with neat silicon and with silicon heat treated up to $300^{\circ} \mathrm{C}$ heated silicon, were similar. This trend is in agreement with the TG results which showed a minimal decrease in silicon content in this heat treatment temperature range. Samples heat treated at temperatures from $350^{\circ} \mathrm{C}$ to $550^{\circ} \mathrm{C}$ showed progressively lower energy outputs. This trend coincides with the decrease in silicon content observed in the TG results in the same range. The DTA results support the notion that the growth of a $\mathrm{SiO}_{2}$ film decreases the reactivity and activity of the silicon. Berger [22] stated that the particle size, the active surface of the oxidizer or fuel, the degree of mixing and fuel to oxidizer ratio are the main parameters influencing pyrotechnic reaction rates. It is possible that by increasing the thickness of the surface oxide layer, the active surface of the silicon is altered, ultimately affecting the DTA response. Another possible 
explanation is that the amount of silicon available per unit mass in the oxidized silicon powder $\left(350^{\circ} \mathrm{C}\right.$ and above) is less than that of the neat silicon powder hence less energy output should be expected [23].

\section{Discussions}

The initial step decrease in hydrogen evolution observed in Figure 1 is postulated to result from the removal of a small surface defects in the passivating oxide layer [13]. These defects can be associated with grain boundary sites as well as silanol terminations ( $\mathrm{Si}-\mathrm{OH})$. The Si-OH surface bonds were shown by Gräf et al. [24] to be electronegative in nature. This induces polarization of the nearby $\mathrm{Si}-\mathrm{Si}$ bonds making them susceptible to nucleophilic attack by water which in turn releases hydrogen gas [24]. Bahruji et al. [13] report that the silanol terminations are known to be metastable in relation to the oxidised surface and therefore mild heating could lead to a dehydration reaction, removing the defects and replacing them with a passivated $\mathrm{SiO}_{2}$ layer with uniform charge distribution. Bahruji et al. [13] proposed Scheme III to explain the effect of mild heating on the nature of the surface of the silicon powder.

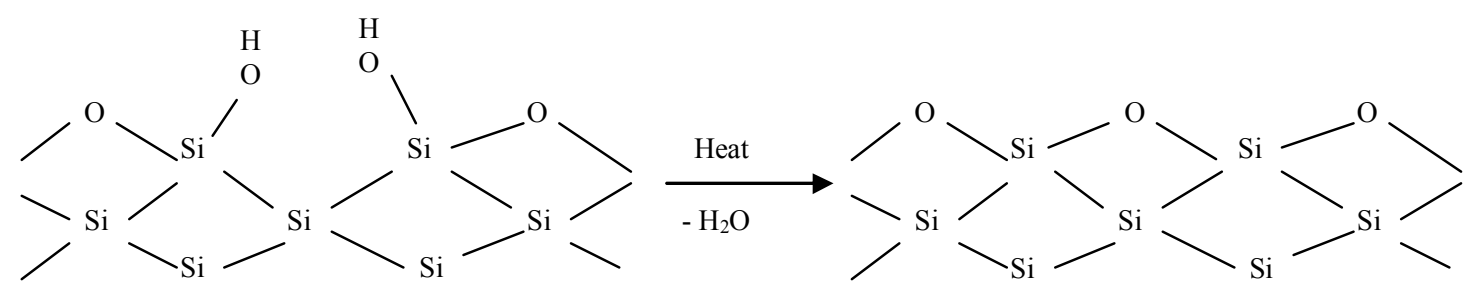

Scheme III: Mechanism proposed by Bahruji et al. [13] for the thermal passivation of silicon by dehydration of silanol groups at the surface. 
The second step-decrease in $\mathrm{H}_{2}$ evolution takes place between $300^{\circ} \mathrm{C}$ and $350^{\circ} \mathrm{C}$. This is attributed to thickening of the $\mathrm{SiO}_{2}$ layer due to increased oxidation rather than mere removal of surface defects. The increased oxide layer thickness represents a greater mass transfer resistance as it limits the rate of oxidant diffusion through it and hence reduces the hydrogen gas evolved. It is however surprising to note that increasing the extent of oxidation beyond $350^{\circ} \mathrm{C}$, had little effect on the amount of hydrogen evolved.

\section{Conclusions}

The effect of heat treatment on the reactivity of commercial silicon powder in water, and also in a pyrotechnic composition, was studied. The heat treatments were conducted isothermally in air for four hours. The reactivity with water was quantified by the amount of hydrogen the silicon dispersion released within one hour. The chemical reactivity and activity were determined as the DTA onset temperature and the reaction heat released by a 20 $\mathrm{wt} \%$ silicon $+80 \mathrm{wt} \%$ lead chromate pyrotechnic composition. Focussed ion beam scanning electron microscopy, FTIR analysis, thermogravimetric analysis, and HF etching showed that the extent of surface oxidation varied with the heat treatment temperature. The onset temperature for silicon oxidation in air was found to be $350^{\circ} \mathrm{C}$. A similar moderate decrease in the amount of hydrogen released was observed for samples heat treated above $75^{\circ} \mathrm{C}$ but below $300^{\circ} \mathrm{C}$. This was attributed to surface passivation, caused in part, by dehydration of the surface silanol groups. Heat treatments conducted at higher temperatures (from $350^{\circ} \mathrm{C}$ to $550^{\circ} \mathrm{C}$ for 4 hours) caused a progressive thickening of the surface oxide layer. However, the amount of $\mathrm{H}_{2}$ evolved again showed just a simple step change to a constant but much lower value at a temperature of ca. $350^{\circ} \mathrm{C}$ (i.e., heating to higher temperatures did not result in a 
further reduction of gas release). The DTA onset temperature for neat silicon was ca. $655^{\circ} \mathrm{C}$. Even with the mild heat treatment at a temperature of $75^{\circ} \mathrm{C}$ this increased by $20^{\circ} \mathrm{C}$. Above $250^{\circ} \mathrm{C}$ the onset temperature increased steadily reaching $725^{\circ} \mathrm{C}$ for silicon samples heat treated at $550^{\circ} \mathrm{C}$. The decrease in the heat of reaction tracked the reduction in silicon content caused by the high temperature heat treatment.

\section{References}

[1] E.-C. Koch, D. Clement, Special Materials in Pyrotechnics: VI. Silicon - An old Fuel with New Perspectives, Prop. Explos. Pyrotech. 2007, 32, 205.

[2] I. M. M Ricco, C. Conradie, W.W. Focke, Alternative Oxidants for Silicon Fuel in Time Delay Detonators, Combust. Sci. Technol. 2004, 176, 1565.

[3] S. K. Chan, N.Y.W. Hsu, R. Oliver, Process for the Preparation of Gas - Generating Compositions, European Patent Application 0735013 A1, 1996, Imperial Chemical Industries, London, GB and ICI Canada Inc, North York Ontario, CA.

[4] C. G. Morgan, C. Rimmington, Manufacture of Pyrotechnic Time Delay Compositions, US Patent, US2010/0037999A1. 2010, African Explosives Limited, Woodmead, Gauteng Province, ZA.

[5] E. P. Boonekamp, J. J. Kelly, J. van de Ven, A. H. M Sondag, The Chemical Oxidation of Hydrogen - Terminated Silicon ( 111) Surfaces in Water Studied in situ with Fourier Transform Infrared Spectroscopy, J. Appl. Phys. 1994, 75, 8121.

[6] M. N. Carcassi, F. Fineschi, Deflagrations of $\mathrm{H}_{2}$-air and $\mathrm{CH}_{4}$-air Lean Mixtures in a Vented Multi-compartment Environment, Energy 2005, 30, 1439.

[7] R. L. Twite, G.P. Bierwagen, Review of Alternatives to Chromate for Corrosion Protection of Aluminium Aerospace Alloys, Prog. Org. Coat. 1998, 33, 91. 
[8] S. Mack, D. Biro, A. Wolf, B. Thaidigsmann, A. Walczak, J. J. Speigelman, P. Preu, Purified Steam for Industrial Thermal Oxidation Processes, 35th Photovoltaic Specialist Conference, June 20-25 2010, Honolulu, Hawaii, 2010.

[9] B. E. Gruvin, T. Johansson, M. E. Hatcher, Low Temperature Oxidation of Silicon Powders, Mater. Sci. Eng. 1985, 71, 363.

[10] L. Debarge, J. P. Stoquert, A. Slaoui, L. Stalmans, J. Poortmans, Rapid Thermal Oxidation of Porous Silicon for Surface Passivation, Mater. Sci. Semicond. Process. 1998, 1,281 .

[11] E. Simoen, C. Gong, N.E. Posthuma, E. van Kerschaver, J. Poortsmans, R. Mertens, ADLTS Study of $\mathrm{SiO}_{2}$ and $\mathrm{SiO}_{2} / \mathrm{SiN}_{\mathrm{x}}$ Surface Passivation of Silicon, J. Electrochem. Soc. 2011, 158, H612.

[12] G. Dingemans, M. C. M. van der Sanden, W. M. M. Kessels, Excellent Si Surface Passivation by Low Temperature $\mathrm{SiO}_{2}$ using an Ultrathin $\mathrm{Al}_{2} \mathrm{O}_{3}$ Capping Film, Phys. Status Solidi RRL 5. 2011, 1, 22.

[13] H. Bahruji, M. Bowker, P. R. Davies, Photoactivated Reaction of Water with Silicon Nanoparticles, Int. J. Hydrogen Energy 2009, 34, 8504.

[14] E. A. Irene, Y.J. van der Meulen, Silicon Oxidation Studies: Analysis of $\mathrm{SiO}_{2}$ Film Growth Rate, J.Electrochem. Soc. 1976, 123, 1380.

[15] V. A. Hackley, U. Paik, B. Kim, S.G. Malghan, Aqueous Processing of Sintered Reaction - Bonded Silicon Nitride: I, Dispersion Properties of Silicon Powder, J. Am. Ceram. Soc. 1997, 80, 1781.

[16] E. A. Irene, Models for the Oxidation of Silicon, Crit. Rev. Solid State 1988, 14, 175.

[17] K. Nakamura, A. Kurokuwa, S. Ichimura, Hydrofluoric Acid Etching of Ultrathin Silicon Oxide Film Fabricated by High Purity Ozone, Thin Solid Films 1999, 343 - 344, 361. 
[18] K. Ilunga, O. del Fabbro, L. Yapi, W. W. Focke, The effect of $\mathrm{Si}_{-} \mathrm{Bi}_{2} \mathrm{O}_{3}$ on the Ignition of the Al-CuO Thermite, Powder Technol. 2011, 205, 97.

[19] S. M. Tichapondwa, W. W. Focke, O. Del Fabbro, S. Mkhize, E. Muller, Suppressing $\mathrm{H}_{2}$ Evolution by Silicon Powder Dispersions, J. Energ. Mater. 2011, 29, 326.

[20] W. K. Na, H. M. Lim, S. H. Huh, S. E. Park, Y-S. Lee, S. H. Lee, Effect of the Average Particle Size and the Surface Oxidation Layer of Silicon on the Colloidal Silica Particle through Direct Oxidation, Mater. Sci. Eng. B. 2009, 163, 82.

[21] P. G. Laye, E. L. Charsley, Thermal Analysis of Pyrotechnics, Thermochim. Acta 1987, 120,325 .

[22] B. Berger, Parameters Influencing the Pyrotechnic Reaction, Prop. Explos. Pyrotech. 2005, 30, 27.

[23] H. Ellern, Military and Civilian Pyrotechnics, Chemical Publishing Company, New York 1968, p. 203.

[24] D. Gräf, M. Grunder, R. Schulz, Reaction of Water with Hydrofluoric Acid Treated Silicon (111) and (100) Surfaces, J. Vac.Sci. Technol. A. 1989, 7, 808.

\section{Acknowledgements}

Financial support from the THRIP programme of the Department of Trade and Industry and the National Research Foundation as well as AEL Mining Services is gratefully acknowledgement. 